\title{
RESEARCH
}

Open Access

\section{The impact of a park refurbishment in a low socioeconomic area on physical activity: a cost-effectiveness study}

Anita Lal ${ }^{*}$ (D), Marj Moodie ${ }^{1}$, Gavin Abbott ${ }^{2}$, Alison Carver ${ }^{3}$, Jo Salmon², Billie Giles-Corti ${ }^{4}$, Anna Timperio ${ }^{2}$ and Jenny Veitch ${ }^{2}$

\begin{abstract}
Background: Physical inactivity is the fourth highest cause of death globally and is a major contributor to increases in healthcare expenditure. Improving public open spaces such as parks in areas of low socio-economic position (SEP) may increase recreational physical activity in disadvantaged populations. We assessed the cost-effectiveness of the installation of a play-space in a large metropolitan park in a low socioeconomic area based on changes in physical activity.

Methods: Observational data of visitor counts and activities undertaken in the park before the installation of the new play-scape (T1), at two months (T2) and 14 months post-installation (T3) were obtained for the intervention and a control park (with no refurbishment) located in a high SEP metropolitan area. Observed sitting, standing, and moderate and vigorous-intensity physical activity were converted to yearly MET-h according to age. Costs of the play-scape and ongoing maintenance were obtained from the organisation managing the refurbishment. The incremental cost-effectiveness ratio (ICER) (ratio of incremental cost to incremental effect) was calculated based on the incremental increase in MET-h from T1 to T3 assuming a 20-year lifetime of the play-scape. Observation counts combining moderate and vigorous activity were used in the sensitivity analysis.
\end{abstract}

Results: When compared with T1, at T3 the new play-scape resulted in an overall incremental net gain of 114,114 MET-h (95\% UI: 80,476 - 146,096) compared with the control park and an incremental cost effectiveness ratio (or cost per MET-h gained per park visitor) of AUD \$0.58 (95\% UI: \$0.44-\$0.80).

The sensitivity analysis combining moderate and vigorous activity into one category showed an increase in estimated incremental MET-h of 118,190 (95\% Cl: 83,528 - 149,583) and a lower incremental cost per MET-h gained of AUD \$0.56 (95\% UI: \$0.43-\$0.77).

Conclusions: Using a benchmark of cost-effectiveness for physical activity interventions of AUD \$0.60-\$1.30, this study suggests that the installation of a play-scape located in a low SEP area is cost-effective based on its potential to facilitate increases in MET-h. It provides much needed preliminary evidence and requires replication elsewhere.

Keywords: Physical activity, Park, Playground, Play-scape, Children, Socioeconomic, Cost-effectiveness

\footnotetext{
* Correspondence: anita.lal@deakin.edu.au

'Deakin University, Geelong, Australia, Deakin Health Economics, Centre for

Population Health Research, Locked Bag 20000, Geelong, VIC 3220, Australia

Full list of author information is available at the end of the article
}

(C) The Author(s). 2019 Open Access This article is distributed under the terms of the Creative Commons Attribution 4.0 International License (http://creativecommons.org/licenses/by/4.0/), which permits unrestricted use, distribution, and reproduction in any medium, provided you give appropriate credit to the original author(s) and the source, provide a link to the Creative Commons license, and indicate if changes were made. The Creative Commons Public Domain Dedication waiver (http://creativecommons.org/publicdomain/zero/1.0/) applies to the data made available in this article, unless otherwise stated. 


\section{Introduction}

Physical inactivity is the fourth highest cause of death globally [1] and is a major contributor to increases in healthcare expenditure [2]. In Australia, only one-third of children undertake the recommended $60 \mathrm{~min}$ of physical activity every day [3], and just $45 \%$ adults engage in $150 \mathrm{~min} /$ week of at least moderate-intensity physical activity [4]. These low prevalence rates are consistent with many other high-income countries globally [5]. There is also consistent evidence of a lower prevalence of moderate- to vigorous-intensity physical activity among adults of lower socio-economic position (SEP) in high income countries [6-8].

Public open spaces, including parks, provide opportunities for physical activity across a range of diverse population groups [9]. Parks with more amenities have been shown to increase use and encourage physical activity $[10,11]$. Yet compared with high SEP neighbourhoods, parks in low SEP areas have been shown to have fewer amenities likely to encourage physical activity [12] and tend to be of lower quality in terms of amenities and aesthetics [13]. It is therefore plausible that improving parks in low SEP areas could help to increase physical activity among disadvantaged populations.

Governments - particularly local government - make significant financial investments to improve and maintain parks. While previous studies have examined changes in park visitation and park-based physical activity after park refurbishment [14-16], there is very little international evidence about whether park refurbishment is an efficient and cost-effective way to allocate resources to increase physical activity [17-19]. Such information is critical given government budgets are often tightly restricted with competing priorities for funding. A limited number of studies in the US have examined the cost-effectiveness of parks including new playgrounds and outdoor exercise equipment and have found that cost-effectiveness ranged from USD 0.105$2.66[14,17,20]$.

A recent Australian study demonstrated a $128 \%$ increase in park visitors observed engaging in physical activity following the installation of a play-scape designed to bring children and accompanying adults back to nature, relative to a control park [21]. The current study aimed to assess the cost-effectiveness of this play-scape installation.

\section{Methods}

The Recording and EValuating Activity in a Modified Park (REVAMP) study was a natural experiment designed to evaluate the impact of the installation of a play-scape, a play area designed with the intent of bringing children and accompanying adults back to nature, in a large metropolitan park (Brimbank Park) in Melbourne, Australia.
The study was registered in the International Randomised International Standard Randomised Controlled Trials Number registry (ISRCTN50745547) and the protocol and main outcomes have been published [21, 22].

\section{Intervention}

The 329 ha intervention park was located $28 \mathrm{~km}$ north-west of Melbourne's Central Business District. It is located in a municipality of extreme socioeconomic disadvantage, with one of the highest percentage of low income families in the state of Victoria [23].

The refurbishment involved the installation of a new play-scape including a large 360 degree swing, traditional swing set, maze, rockers, sandpit, nature play area, climbing equipment, landscaping, and various sculptures. The play-scape was designed to be accessible for children with disabilities and to encourage visitors to connect with both the natural environment and the indigenous cultural heritage of the region. The play-scape area was originally an open space area with no features or amenities. The refurbishment of the park occurred between September 2013 and February 2014.

\section{Control}

The control park (Westerfolds Park, 120 ha) was located $22 \mathrm{~km}$ east of Melbourne's Central Business District in a high SEP area. The investigators were unable to find a similar sized park in a low SEP area that was not undergoing renovations during the study period, however the selected park had similar infrastructure and settings for being active, such as paths for walking or cycling, open space areas and a single adventure style playground. In addition, both parks had other similar amenities such as toilets, car-parking, a variety of picnic shelters, tables and barbeque areas. A more detailed description of the features within the two parks can be found elsewhere [24]. It is recognised that it may be challenging to identify a perfectly matched control site and a compromise may be necessary $[25,26]$.

\section{Assessment of benefits}

Primary outcome The outcome of interest was a change in the number of visitors across three age groups (1-12 years, $13-20$ years and $>21$ years) observed engaging in physical activity, measured in metabolic equivalent hours (MET-h). Observational data of park visitors were recorded within both parks over eight days, including four weekdays and four weekend days using a modified version of the System for Observing Play and Recreation in Communities (SOPARC) [21, 27]. As described previously [28], observations were conducted at hourly intervals between $7.30 \mathrm{am}-4.30 \mathrm{pm}$ on weekdays and between $8.30 \mathrm{am}-4.30 \mathrm{pm}$ on weekend days. Baseline 
assessments were conducted in April-May 2013 (T1 pre-park refurbishment), first follow-up measures were conducted in April-May 2014 (T2 - two months after the completion of refurbishment) and second follow-up measures were conducted in April-May 2015 (T3-14 months after the completion of refurbishment). Each data collection phase took place on the same days at both parks and at the same time of the year (autumn) to account for potential seasonal effects.

Research staff recorded each individual in specified target areas according to their estimated age group and the activity they were performing (sitting, standing, and moderate and vigorous-intensity physical activity). The target areas included the new play-scape at the intervention park and the playground at the control park, as well as other areas within the parks such as open spaces and picnic shelters. For the primary analysis, only the counts at the newly installed play-scape area at the intervention park and the playground area at the control park were used, not the total counts across all recorded target areas.

Calculation of MET- hours At each park, an average hourly count of park visitors engaged in each activity was obtained. The counts of people doing activity at a particular moment in time was used as an estimate of the total person hours of that activity during each one hour period (See Additional file 1 for detailed counts of people). For the purpose of this paper, MET values were assigned to observed sitting, standing, and moderate and vigorous-intensity physical activity according to age [29, 30] (Table 1). For each activity, MET values for children aged 6-9 and 10-12 years were averaged to obtain a value for all children aged 12 years and under. Similar calculations were carried out for MET values for the 1320 year category.

To obtain an estimate of annual use, the average counts on weekends and weekdays were multiplied by the number of weekend days and weekdays in a year. It was assumed that park visitation would not occur on days of significant rainfall, therefore to account for the average of 20 days of rain $>10 \mathrm{~mm}$ per year in Melbourne, [31] we based our calculations on 49 weeks of the year.

For example, to calculate the total number of MET-h for children, the average counts of children per day engaged in each category of physical activity were multiplied by the number of MET-h according to age. This was then multiplied by the number of days in 49 weeks.

The main analysis used data from baseline (T1) and the final follow up (T3), which took place more than a year after the refurbishment was completed, and was thought to more accurately reflect the average number of visitors to be sustained over time.

\section{The economic evaluation}

A cost-effectiveness analysis was conducted to determine the incremental cost-effectiveness ratio (ICER) per unit increase in MET-h gained, using the ratio of incremental cost to incremental effect between observed park-based physical activity at the play-scape/playground area at T1 vs T3, relative to the control park. ICERs were calculated by determining the increment in MET-h generated per cost of the play-scape, per year.

Table 2 outlines the general methodology of the economic evaluation. The intervention was assumed to be operating in 'steady state' at T3 (i.e. running at its full effectiveness potential with typical numbers of visitors) and measured against pre-refurbishment. Discounting in cost-effectiveness analysis allows for fair comparisons of interventions when costs and outcomes occur at different times [32]. After year one, each years' costs were discounted at a rate of $3 \%$.

\section{Costs}

The costs of the play-scape installation and its yearly maintenance, as well as maintenance costs for the control park, were obtained from Parks Victoria, the organisation that managed the refurbishment (Table 3). Refurbishment costs were inflated to 2017 prices using the relevant CPI [33].

\section{Cost-effectiveness analysis}

To calculate the incremental net increase in MET-h the following formula was used:

(Intervention T3 MET-h - Intervention T1 MET-h) (Control T3 MET-h - Control T1 MET-h)

The costs of the play-scape were amortized over 20 years and then added to the yearly maintenance costs of $\$ 7700$ (the difference between the control and intervention park maintenance costs). The net cost of the intervention was divided by the incremental net increase in

Table 1 MET-h values applied to each activity level by age group

\begin{tabular}{llllll}
\hline & Sitting & Standing & Moderate activity & Vigorous activity & Average of moderate and vigorous activity \\
\hline Up to 12 years & $1.5^{1}$ & 1.7 & $6.0^{2}$ & $7.3^{3}$ & 6.7 \\
13-20 years & $1.5^{1}$ & 1.7 & $6.3^{2}$ & $7.7^{3}$ & 7.0 \\
20 years and over & 1.5 & 2.3 & $3.5^{4}$ & $7.0^{5}$ & 5.3 \\
\hline
\end{tabular}

${ }^{1}$ Sitting quietly [46]; ${ }^{2}$ Obstacle/locomotor course-moderate [46]; ${ }^{3}$ obstacle/locomotor course-vigorous [46]; ${ }^{4}$ walking for pleasure [30]; ${ }^{5}$ jogging [30] 
Table 2 General methods of the economic evaluation

\begin{tabular}{ll}
\hline Parameter & Method \\
\hline Perspective & Local government perspective \\
Study design & Cost-effectiveness analysis \\
Monetary unit of measurement & Australian Dollars \\
Base year & 2017 \\
Unit of measurement of & Metabolic equivalent hours (MET-h) \\
outcomes & gained \\
Comparator & Control park, no refurbishment \\
Discounting & $3 \%$ \\
\hline
\end{tabular}

MET-h. The incremental cost-effectiveness ratio was expressed as the cost per unit increase in MET-h. This is equivalent to the incremental cost per MET-h gained per park visitor.

\section{Sensitivity analyses}

To test how robust the results were around the key assumptions, probabilistic uncertainty analysis was conducted around key parameters (Table 3). Means and 95\% uncertainty intervals for yearly estimated MET-h and incremental MET-h were reported based on 2000 iterations using Ersatz version 1.35 software. Separate sensitivity analyses were conducted using combined counts of visitors observed engaging in moderate and vigorous physical activity for each age group and an average of moderate and vigorous MET-h (Table 1).

We tested the uncertainty surrounding the incremental cost-effectiveness ratio by using $\mathrm{T} 2$ vs $\mathrm{T} 1$ (instead of T3 vs T1) for the change in MET-h. Separate analysis was also conducted based on the observed visitations across 10 target areas [21] (rather than just the play-scape) using $\mathrm{T} 1$ vs $\mathrm{T} 3$, to test whether the play-scape installation had an effect on physical activity performed in other areas of the park. The life of the new play-scape was also varied using 10 and 15 years (instead of 20 years) and zero discounting of costs was modelled.

\section{Results}

Compared with T1, a large overall increase in MET-h at T3 was observed at the intervention park, resulting in a net gain of 114,114 MET-h $(95 \% \mathrm{CI}=80,476-146,096)$ relative to the control park. The greatest increases in MET- $h$ at the intervention play-scape were amongst children, with incremental gains 30 times the MET-h at baseline (Table 4). There was also a four-fold incremental increase in MET-h among adults. The average number of MET-h gained per play-scape visitor per year was 131. The change in MET-h resulted in an incremental cost-effectiveness ratio of AUD \$0.58 (95\% UI \$0.44-\$0.80) per MET-h gained, when measured against the control (Table 5).

Assuming 20 years' amortization, the incremental annual costs of the installation and maintenance of the play-scape were $\$ 64,155$.

\section{Sensitivity and uncertainty analyses}

When moderate and vigorous activity were combined into one category (combined MVPA), the incremental gain in total estimated MET-h was slightly higher at $118,190$ (95\% UI: $83,528-149,583)$ resulting in a slightly lower cost per MET-h of \$0.56 (95\%UI: \$0.43-\$0.77). At $\mathrm{T} 2$, the incremental gain in total estimated MET-h was 113,282 (95\%UI: 74,383 - 152,731) resulting in a similar cost-effectiveness ratio of $\$ 0.59$ (95\%UI: $\$ 0.42-\$ 0.80)$

Table 3 Key model variables

\begin{tabular}{|c|c|c|}
\hline Parameters & Mean values & Data source and assumptions \\
\hline \multicolumn{3}{|l|}{ Intervention effect estimates } \\
\hline $\begin{array}{l}\text { Difference in mean observations of children, adolescents and adults } \\
\text { per day at } T 1 \text { and } T 3^{*}\end{array}$ & Additional file 1 & $\begin{array}{l}\text { Veitch et al. [21] Uncertainty analysis used PERT } \\
\text { distributions of observations (Additional file 1) }\end{array}$ \\
\hline $\begin{array}{l}\% \text { of people engaged in physical activity from observations of } \\
\text { children, adolescents and adults per day at } T 1 \text { and } \mathrm{T}^{*}\end{array}$ & Additional file 1 & $\begin{array}{l}\text { Veitch et al. [21] Assume one hour duration of activity to } \\
\text { convert to a MET-h }\end{array}$ \\
\hline \multicolumn{3}{|l|}{ Intervention cost estimate } \\
\hline Cost of design and construction of play-scape & $\$ 1,165,105$ & \multirow{2}{*}{$\begin{array}{l}\text { Personal communication Parks Victoria. } 2014 \text { costs } \\
\text { converted to } 2017 \text { using CPI [33] }\end{array}$} \\
\hline Annual maintenance & $\$ 12,700$ & \\
\hline Life of playground & 20 years & Assume 20 years (varied in sensitivity analysis) \\
\hline \multicolumn{3}{|l|}{ Control cost estimate } \\
\hline Annual maintenance & $\$ 5000$ & Personal communication Parks Victoria \\
\hline \multicolumn{3}{|l|}{ Sensitivity analysis } \\
\hline $\begin{array}{l}\text { Difference in mean observations of children, adolescents and adults } \\
\text { per day between } \mathrm{T} 2 \text { and } \mathrm{T} 1\end{array}$ & Additional file 1 & $\begin{array}{l}\text { Veitch et al. [21] Uncertainty analysis used PERT } \\
\text { distributions of observations (Additional file 1) }\end{array}$ \\
\hline Life of playground & 10 and 15 years & Varied for less conservative estimates \\
\hline
\end{tabular}

Notes: ${ }^{*} \mathrm{~T} 1$ : baseline, T2: first follow up at 2 months, T3: second follow up at 14 months, CPI: consumer price index. PERT: a probability distribution defined by minimum, most likely and maximum 
Table 4 Mean MET-h at baseline and estimated incremental MET-h gained from observed play-scape visitors by age group

\begin{tabular}{|c|c|c|c|c|c|c|c|c|}
\hline & \multicolumn{3}{|l|}{ Intervention park } & \multicolumn{3}{|l|}{ Control park } & \multicolumn{2}{|c|}{ Incremental changes in MET-h } \\
\hline & $\begin{array}{l}\text { Mean MET-h } \\
\text { T1 (95\% UI) }\end{array}$ & $\begin{array}{l}\text { Mean MET-h } \\
\text { T2 (95\% UI) }\end{array}$ & & $\begin{array}{l}\text { Mean MET-h } \\
\text { T1 (95\% UI) }\end{array}$ & $\begin{array}{l}\text { Mean MET-h } \\
\text { T2 (95\% UI) }\end{array}$ & $\begin{array}{l}\text { Mean MET-h T3 } \\
(95 \% \text { UI) }\end{array}$ & $\begin{array}{l}\text { Mean MET-h at } \\
\text { T2* }^{*}(95 \% \text { UI) }\end{array}$ & $\begin{array}{l}\text { Mean MET-h at } \\
\text { T3* }^{*}(95 \% \text { UI) }\end{array}$ \\
\hline (15) & $\begin{array}{c}2164 \\
(1331-3010)\end{array}$ & $\begin{array}{c}62,742 \\
(46,374-80,688)\end{array}$ & $\begin{array}{c}53,279 \\
(49,417-84,9\end{array}$ & $\begin{array}{r}54,5 \\
(45,153-\end{array}$ & $\begin{array}{c}44,758 \\
(30,276-58,453)\end{array}$ & $\begin{array}{r}36 \\
(28573\end{array}$ & $\begin{array}{r}70, \\
(45645-\end{array}$ & $\begin{array}{r}68 \\
(48,336\end{array}$ \\
\hline $\begin{array}{l}\text { dolescents } \\
3-20 \text { years) }\end{array}$ & 0 & $\begin{array}{c}7056 \\
(5215-9074)\end{array}$ & $\begin{array}{c}6318 \\
(4617-7919)\end{array}$ & $\begin{array}{c}1274 \\
(1075-1479)\end{array}$ & $\begin{array}{c}1931 \\
(1307-2522)\end{array}$ & $\begin{array}{c}772 \\
(598-954)\end{array}$ & $\begin{array}{c}5135 \\
(3152-7267)\end{array}$ & $\begin{array}{c}6820 \\
(5125-8429)\end{array}$ \\
\hline tits & $\begin{array}{c}9345 \\
(1752-4146)\end{array}$ & $\begin{array}{c}42,397 \\
(31,336-54,524)\end{array}$ & $\begin{array}{c}43,471 \\
(31,769-54,486)\end{array}$ & $\begin{array}{c}16,096 \\
(13,331-19,052)\end{array}$ & $\begin{array}{c}12,952 \\
(8761-16,915)\end{array}$ & $\begin{array}{c}11,584 \\
(8976-14,308)\end{array}$ & $\begin{array}{c}36,291 \\
(23201-50,123)\end{array}$ & $\begin{array}{c}38,638 \\
(25,796-51,009)\end{array}$ \\
\hline btal & $\begin{array}{c}11,509 \\
(7080-16,012)\end{array}$ & $\begin{array}{c}112,196 \\
(82,925-144,286)\end{array}$ & $\begin{array}{c}102,997 \\
75,271-129,096)\end{array}$ & $\begin{array}{c}71,887 \\
(59,616-85,019)\end{array}$ & $\begin{array}{c}59,332 \\
(39,861-77,710)\end{array}$ & $\begin{array}{c}49,231 \\
(38,147-60,809)\end{array}$ & $\begin{array}{c}113,282 \\
(74,383-152,731)\end{array}$ & $\begin{array}{c}114,114 \\
(80,476-146,0\end{array}$ \\
\hline
\end{tabular}

Notes: $\mathrm{UI}=$ Uncertainty interval, $\mathrm{T} 1$ = baseline, $\mathrm{T} 2=2$ months after play-scape installation, $\mathrm{T} 3=14$ months after play-scape installation

Means reported from probabilistic uncertainty analysis based on 2000 iterations. *Incremental MET-h takes into account changes in visitations at the control park and changes due to the intervention

compared with T3 vs T1 (Table 5). At T2, the average number of MET-h gained per play-scape visitor per year was 118.

Reducing the amortization period from 20 years decreased the cost-effectiveness. Assuming 15 years amortization of the play-scape costs resulted in an increase in the cost-effectiveness ratio to approximately \$0.77 per MET-h (95\%UI: \$0.59-\$1.06). When amortization was further reduced to 10 years, the cost-effectiveness ratio increased to $\$ 1.15$ per MET-h (95\%UI: \$0.88-\$1.59). Reducing the discount rate from 3 to $0 \%$ had no effect on the cost-effectiveness ratios as the majority of the costs occurred in the first year. When all target areas were considered (not just the play-scape), the incremental increase in MET-h from T1 to T3 was 131,477 at a cost of $\$ 0.86$ (95\% UI: $0.24-4.34$ ) per MET-h gained.

\section{Discussion}

We estimated that 14 months after the installation of the new play-scape, the average cost per MET-h gained per person was $\$ 0.58$ (95\% UI \$0.44-\$0.80) based on amortization over 20 years. Using Wu et al's methodology, we converted to Australian currency the cost-effectiveness benchmark of interventions targeting physical inactivity, and based on physical inactivity costing $2.4 \%-5 \%$ of annual healthcare costs [34] of $\$ 7096$ per capita [35] and an average recommended MET-h per year of 390 MET-h. This gave a cost-effectiveness threshold ranging from approximately $\$ 0.60$ to $\$ 1.30$ AUD per MET-h gained (for adults). The REVAMP intervention could therefore be considered cost-effective.

The increase in MET-h measured across all ages was 113,282 (95\%UI: $(74,383-152,731)$ with children contributing $60 \%$ of the overall increase. Substantial increases in MET-h were also measured in adults potentially because of the increase in adults visiting the park to accompany children to the play-scape. Sensitivity analysis using an average of moderate and vigorous activity values (combined MVPA) led to more favourable results, because the MET-h values increased for moderate activity. When analysing all target areas, the results were less favourable than for the new play-scape area alone. The higher cost-effectiveness ratio reflects a larger range in the number of observed visitors and therefore more variability in the MET-h gained. Moreover, when the amortization period is reduced, the intervention becomes less cost-effective. However, local governments use a notional economic life of 20 years for playground equipment [36].

Our study compares favourably to previous studies examining the cost-effectiveness of new and refurbished parks in the US. Vacant lots converted to pocket parks with new playground equipment had cost-effectiveness ratios ranging from USD 0.43 to 2.63 /MET-h [20]. Renovation of parks with new playgrounds ranged from USD 0.27 to 2.66 /MET-h depending on the size of the park [14]. The cost-effectiveness of outdoor exercise

Table 5 Cost-effectiveness results and sensitivity analyses

\begin{tabular}{llll}
\hline Comparison time periods, area & Amortization period of play-scape & Cost-effectiveness ratio $(95 \%$ UI) & Annual costs \\
\hline T3 vs T1 play-scape & 20 years & $\$ 0.58(\$ 0.44-\$ 0.80)$ & $\$ 64,155$ \\
T3 vs T1 play-scape (MVPA)* & 20 years & $\$ 0.56(\$ 0.43-\$ 0.77)$ & $\$ 64,155$ \\
T2 vs T1 play-scape & 20 years & $\$ 0.59(\$ 0.42-\$ 0.86)$ & $\$ 64.155$ \\
T3 vs T1 all target areas & 20 years & $\$ 0.86(\$ 0.24-\$ 4.34)$ & $\$ 64,155$ \\
T3 vs T1 play-scape & 15 years & $\$ 0.77(\$ 0.59-\$ 1.06)$ & $\$ 85,540$ \\
T3 vs T1 play-scape & 10 years & $\$ 1.15(\$ 0.88-\$ 1.30)$ & $\$ 128,310$ \\
\hline
\end{tabular}

Notes: * used a combined moderate and vigorous physical activity category 
equipment in parks designed for people aged 13 years and older was found to be cost-effective at USD 0.105/ MET-h [17].

A review that examined the cost-effectiveness of interventions to increase physical activity, found that children's interventions (mainly in school settings) ranged from $\$ 0.09$ to $\$ 1.20$ per MET-h gained (converted to AUD 2017 using purchasing power parities [37]) and our findings fall within this range [18]. The interventions analysed in that review included health and nutrition programs $\$ 0.09-\$ 0.56$ per MET-h gained [38, 39], health education plus provision of play equipment such as balls during breaks $\$ 0.68$ per MET-h gained [40], and a program to encourage active transport to school $\$ 1.20$ per MET-h gained [41]. Apart from the active transport program, these interventions did not involve major set up costs. The current intervention, and built environment changes in parks more generally, are long lasting and have the potential for wide population reach.

One of the strengths of the current study is the comprehensive nature of the observational data on which the analysis is based. Observations were conducted over an eight day period, four days beyond the minimum recommendation for obtaining robust measures of park visitation [42], with at least nine time points at each park per day. Strong inter-rater reliability was also achieved [21]. We also acknowledge some limitations to our study. The park observations were conducted once per hour and the count of people doing activity at a particular moment in time was used as an estimate of the total person hours of that activity during that one hour period. It is possible that the observations overestimate the amount of physical activity being undertaken, but equally may also underestimate it (e.g. visitors may have been observed sitting but were jogging for the rest of their visit). The observations are likely to be conservative as it was only possible to observe people in specified target areas and not the whole park and the observations also omitted visitors who came and left without being counted (e.g. they visited during the hour between observations). We have also assumed that the observations were representative of park visitations over a 49-week year, but it is important to acknowledge that observations conducted on other days, times and seasons may have provided different results. The study was conducted in late autumn (fall) in Melbourne, and higher numbers of visitors would be expected in spring and summer when the weather is warmer.

Further, the study findings are from one very large metropolitan park in Melbourne, Australia, which may limit generalisability of the results to other parks of varying sizes and amenities. Although the control park was located in a higher SEP area than the intervention park, the study design somewhat alleviated differences in SEP as the objective of the REVAMP study was to compare differences in changes in park visitation and park-based physical activity between the intervention and control park. The control park was located approximately $35 \mathrm{~km}$ from the intervention park via the road network therefore it is unlikely that visitors to the control park would have 'migrated' to the intervention park after the play-scape installation. However, during the observations it was not possible to determine where the visitors lived or which parks they visited previously.

Other benefits of physical activity that would increase the cost-effectiveness of the refurbishment, such as improved quality of life, mental health, social interaction, safety/injury prevention and academic performance in children $[43,44]$ have not been included in our study. We also did not measure the substantial long-term health care costs savings, which stem from increased physical activity [45] although this could be a topic for future research. T3 observations were conducted 14 months after the play scape installation. Future cost-effectiveness studies may benefit from a longer follow-up period.

The park refurbishment was designed specifically for children and unsurprisingly the increases in MET-h among adolescents were small. Future studies could examine the impact of designing parks to optimise physical activity among adolescents, adults and older adults. Outdoor exercise equipment in parks, for example, has been shown to be effective at increasing physical activity in adults, as well as being cost-effective [17].

\section{Conclusions}

This study provides much needed evidence for local and state governments that the installation of a new play-scape in a metropolitan park located in an area of socioeconomic disadvantage appears to be a cost-effective intervention to facilitate greater levels of physical activity in the community. Other jurisdictions considering the installation of a new play-space in a park setting should be encouraged by these findings, which highlight the opportunity to increase park-based physical activity through investment in park refurbishment. However, replication of this study with parks of varying size, location and amenity is important, and future natural experiment studies are encouraged.

\section{Additional file}

Additional file 1: STROBE (Strengthening The Reporting of OBservational Studies in Epidemiology) Checklist (PDF 523 kb) 


\section{Acknowledgements}

Not applicable.

\section{Funding}

AL and MM were supported by National Health and Medical Research Council, Centre for Research Excellence in Obesity Policy and Food Systems grant CRE 1041020. JV is supported by an Australian National Heart Foundation Future Leader Fellowship (ID 101928). The REVAMP study was supported by an Australian Research Council Linkage Grant (LP120200396) and included four partners: Parks Victoria, the Victorian Health Promotion Foundation (VicHealth), Brimbank City Council and City West Water. BGC is supported by an NHMRC Senior Principal Research Fellowship \#1107672.

\section{Availability of data and materials}

All data generated or analysed during this study are included in this published article [and its additional information files].

\section{Authors' contributions}

Conceptualization: JV, AL, MM. Data curation: GA. Formal analysis: AL. Funding acquisition: JV, AT, JS, AC, BGC. Methodology: AL, MM, JV, JS, AT, BGC. Supervision: MM, JV. Validation: MM.

Writing - original draft: AL, MM. Writing - review \& editing: JV, GA, AC, AT, JS, BGC. All authors read and approved the final manuscript.

\section{Ethics approval and consent to participate}

Ethics approval for the REVAMP study was obtained from Deakin University Human Ethics Advisory Group, HEAG-H 46_2012: Assessing park use and physical activity in public places.

\section{Consent for publication}

\section{Not applicable.}

\section{Competing interests}

The authors declare that they have no competing interests.

\section{Publisher's Note}

Springer Nature remains neutral with regard to jurisdictional claims in published maps and institutional affiliations.

\section{Author details}

'Deakin University, Geelong, Australia, Deakin Health Economics, Centre for Population Health Research, Locked Bag 20000, Geelong, VIC 3220, Australia. ${ }^{2}$ Institute for Physical Activity and Nutrition (IPAN), School of Exercise and Nutrition Sciences, Deakin University, Geelong, Australia. ${ }^{3}$ Mary MacKillop, Australian Catholic University, Institute for Health Research, Melbourne, Australia. ${ }^{4}$ Centre for Urban Research, RMIT University, Melbourne, Australia.

Received: 25 July 2018 Accepted: 27 February 2019

Published online: 08 March 2019

\section{References}

1. Kohl HW 3rd, Craig CL, Lambert EV, Inoue S, Alkandari JR, Leetongin G, et al. The pandemic of physical inactivity: global action for public health. Lancet. 380(9838):294-305.

2. Ding D, Lawson KD, Kolbe-Alexander TL, Finkelstein EA, Katzmarzyk PT, van Mechelen W, et al. The economic burden of physical inactivity: a global analysis of major non-communicable diseases. Lancet. 2013;388(10051): $1311-24$.

3. Australian Bureau of Statistics. Key Findings - Australian Health Survey Physical activity, 2011-12. In: Canberra; 2013.

4. Australian Bureau of Statistics. Australian health survey 2014-15. In: Canberra; 2015.

5. Hallal PC, Andersen LB, Bull FC, Guthold R, Haskell W, Ekelund U. Global physical activity levels: surveillance progress, pitfalls, and prospects. Lancet. 2012;380(9838):247-57.

6. Gidlow C, Johnston LH, Crone D, Ellis N, James D. A systematic review of the relationship between socio-economic position and physical activity. Health Educ J. 2006;65(4):338-67.

7. Bauman AE, Reis RS, Sallis JF, Wells JC, Loos RJF, Martin BW. Correlates of physical activity: why are some people physically active and others not? Lancet. 2012;(9838):258.
8. Bauman A, Ma G, Cuevas F, Omar Z, Waqanivalu T, Phongsavan P, et al. Cross-national comparisons of socioeconomic differences in the prevalence of leisure-time and occupational physical activity, and active commuting in six Asia-Pacific countries. J Epidemiol Community Health. 2011;65(1):35.

9. Sallis JF, Cerin E, Conway TL, Adams MA, Frank LD, Pratt M, et al. Physical activity in relation to urban environments in 14 cities worldwide: a crosssectional study. Lancet. 2016;387(10034):2207-17.

10. Giles-Corti B, Broomhall MH, Knuiman M, Collins C, Douglas K, Ng K, et al. Increasing walking: how important is distance to, attractiveness, and size of public open space? Am J Prev Med. 2005;28(2 Suppl 2):169-76. https://doi. org/10.1016/j.amepre.2004.10.018.

11. Edwards N, Hooper P, Knuiman M, Foster S, Giles-Corti B. Associations between park features and adolescent park use for physical activity. Int J Behav Nutr Phys Act. 2015;12:21. https://doi.org/10.1186/s12966-015-0178-4.

12. Schipperijn J, Bentsen P, Troelsen J, Toftager M, Stigsdotter UK. Associations between physical activity and characteristics of urban green space. Urban For Urban Green. 2013;12(1):109-16.

13. Crawford D, Timperio A, Giles-Corti B, Ball K, Hume C, Roberts R, et al. Do features of public open spaces vary according to neighbourhood socioeconomic status? Health and place. 2008;14(4):889-93.

14. Cohen DA, Han B, Isacoff J, Shulaker B, Williamson S, Marsh T, et al. Impact of park renovations on park use and park-based physical activity. J Phys Act Health. 2015;12(2):289-95.

15. Veitch J, Ball K, Crawford D, Abbott GR, Salmon J. Park improvements and park activity a natural experiment. Am J Prev Med. 2012;42(6):616-9.

16. Bohn-Goldbaum EE, Phongsavan P, Merom D, Rogers K, Kamalesh V, Bauman AE. Does playground improvement increase physical activity among children? A quasi-experimental study of a natural experiment. J Environ Public Health. 2013;2013:109841.

17. Cohen DA, Marsh T, Williamson S, Golinelli D, McKenzie TL. Impact and costeffectiveness of family fitness zones: a natural experiment in urban public parks. Health and place. 2012;18(1):39-45.

18. Laine J, Kuvaja-Kollner V, Pietila E, Koivuneva M, Valtonen H, Kankaanpaa E. Cost-effectiveness of population-level physical activity interventions: a systematic review. Am J Health Promot : AJHP. 2014;29(2):71-80.

19. National Institute for Health and Care Excellence. Physical activity and the environment update. Effectiveness and cost effectiveness evidence review 3: park, Neighbourhood and multicomponent interventions. UK: NICE; 2018.

20. Cohen DA, Marsh T, Williamson S, Han B, Derose KP, Golinelli D, et al. The potential for pocket parks to increase physical activity. Am J Health Promot. 2014;28(3 Suppl):S19-26. https://doi.org/10.4278/ajhp.130430-QUAN-213.

21. Veitch J, Salmon J, Crawford D, Abbott G, Giles-Corti B, Carver A, et al. The REVAMP natural experiment study: the impact of a play-scape installation on park visitation and park-based physical activity. Int J Behav Nutr Phys Act. 2018;15(1):10 doi: .1186/s12966-017-0625-5.

22. Veitch J, Salmon J, Carver A, Timperio A, Crawford D, Fletcher E, et al. A natural experiment to examine the impact of park renewal on park-use and park-based physical activity in a disadvantaged neighbourhood: the REVAMP study methods. BMC Public Health. 2014;14:600. https://doi.org/10. 1186/471-2458-14-600

23. Australian Bureau of Statistics. 2033.0.55.001 Socio-Economic Indexes for Australia (SEIFA). Canberra; 2016.

24. Veitch J, Carver A, Abbott G, Giles-Corti B, Timperio A, Salmon J. How active are people in metropolitan parks? An observational study of park visitation in Australia. BMC Public Health. 2015;15:610. https://doi.org/10.1186/s12889-015-1960-6.

25. Veitch J, Salmon J, Giles-Corti B, Crawford D, Dullaghan K, Carver A, et al. Challenges in conducting natural experiments in parks-lessons from the REVAMP study. Int J Behav Nutr Phys Act. 2017;14(1):5. https://doi.org/10. 1186/s12966-016-0460-0

26. Petticrew M, Cummins S, Ferrell C, Findlay A, Higgins C, Hoy C, et al. Natural experiments: an underused tool for public health? Public Health. 2005; 119(9):751-7. https://doi.org/10.1016/j.puhe.2004.11.008.

27. McKenzie TL, Cohen DA, Sehgal A, Williamson S, Golinelli D. System for observing play and recreation in communities (SOPARC): reliability and feasibility measures. J Phys Act Health. 2006;3(s1):S208-s22.

28. Veitch J, Salmon J, Crawford D, Abbott G, Giles-Corti B, Carver A, et al. The REVAMP natural experiment study: the impact of park refurbishment on park visitation and park-based physical activity. IJBNPA. 2018;15(10).

29. Harrell JS, McMurray RG, Baggett CD. Energy costs of physical activities in children and adolescents. Med Sci Sports Exerc. 2005;37(2):329-36. 
30. Ainsworth B, Haskell W, Herrmann S, Meckes N, Bassett D, Tudor-Locke C, et al. The compendium of physical activities tracking guide Arizona: Healthy Lifestyles Research Center,College of Nursing \& Health Innovation, Arizona State University; 2011. [cited 16 August, 2017].

31. Bureau of Meteorology. Climate statistics for Australian locations Canberra: commonwealth government; 2017 [cited 16 August, 2017]. Available from: http://www.bom.gov.au/dimate/data/index.shtml?bookmark=200

32. Drummond MF. Methods for the economic evaluation of health care programmes. Oxford: Oxford University Press; 2005.

33. Australian Bureau of Statistics. Consumer Price Index. Australia. In: Canberra; 2017.

34. Wu S, Cohen D, Shi Y, Pearson M, Sturm R. Economic analysis of physical activity interventions. Am J Prev Med. 2011;40(2):149-58.

35. Australian Institute of Health and Welfare. Health expenditure Australia 2015-16. Health and welfare expenditure series no. 58. Cat. no. HWE 68. Canberra: AlHW; 2017.

36. Knox City Council. Playground asset management plan. Melbourne: Knox City Council; 2013.

37. OECD. Purchasing power parities (PPP) (indicator) 2018 [Cited 6 April 2018]. Available from: doi: https://doi.org/10.1787/1290ee5a-en.

38. McKenzie TL, Nader PR, Strikmiller PK, Yang M, Stone EJ, Perry CL, et al. School physical education: effect of the child and adolescent trial for cardiovascular health. Prev Med. 1996;25(4):423-31.

39. Manios Y, Kafatos I, Kafatos A. Ten-year follow-up of the Cretan health and nutrition education program on children's physical activity levels. Prev Med. 2006;43(6):442-6 Epub 2006 Jul 27.

40. Verstraete SJ, Cardon GM, De Clercq DL, De Bourdeaudhuij IM. A comprehensive physical activity promotion programme at elementary school: the effects on physical activity, physical fitness and psychosocial correlates of physical activity. Public Health Nutr. 2007;10(5):477-84.

41. Moodie M, Haby MM, Swinburn B, Carter R. Assessing cost-effectiveness in obesity: active transport program for primary school children--TravelSMART schools curriculum program. J Phys Act Health. 2011;8(4):503-15.

42. Cohen DA, Setodji C, Evenson KR, Ward P, Lapham S, Hillier A, et al. How much observation is enough? Refining the administration of SOPARC. J Phys Act Health. 2011;8(8):1117-23.

43. Sallis JF, Spoon C, Cavill N, Engelberg JK, Gebel K, Parker M, et al. Cobenefits of designing communities for active living: an exploration of literature. The international journal of behavioral nutrition and physical activity. 2015;12:30

44. Booth JN, Leary SD, Joinson C, Ness AR, Tomporowski PD, Boyle JM, et al. Associations between objectively measured physical activity and academic attainment in adolescents from a UK cohort. Br J Sports Med. 2014;48(3): 265.

45. Lee BY, Adam A, Zenkov E, Hertenstein D, Ferguson MC, Wang Pl, et al. Modeling the economic and health impact of increasing Children's physical activity in the United States. Health affairs (Project Hope). 2017;36(5):902-8.

46. Butte NF, Watson KB, Ridley K, Zakeri IF, McMurray RG, Pfeiffer KA, et al. A youth compendium of physical activities: activity codes and metabolic intensities. Med Sci Sports Exerc. 2018;50(2):246-56. https://doi.org/10.1249/ MSS.0000000000001430.

\section{Ready to submit your research? Choose BMC and benefit from:}

- fast, convenient online submission

- thorough peer review by experienced researchers in your field

- rapid publication on acceptance

- support for research data, including large and complex data types

- gold Open Access which fosters wider collaboration and increased citations

- maximum visibility for your research: over $100 \mathrm{M}$ website views per year

At BMC, research is always in progress.

Learn more biomedcentral.com/submissions 